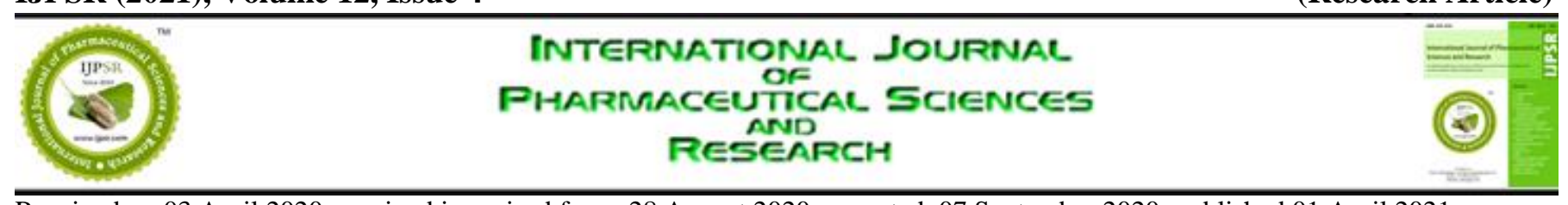

Received on 03 April 2020; received in revised form, 28 August 2020; accepted, 07 September 2020; published 01 April 2021

\title{
DEVELOPMENT AND VALIDATION OF NOVEL UV SPECTROPHOTOMETRIC METHOD FOR THE DETERMINATION OF MEBENDAZOLE IN PHARMACEUTICAL FORMULATION
}

\author{
Saurabh Shrivastava * and Chanchal Deep Kaur
}

Shri Rawatpura Sarkar Institute of Pharmacy, Kumhari, Durg - 490042, Chhattisgarh, India.

Keywords:

Mebendazole, ICH guidelines, Accuracy, Precision, Validation

Correspondence to Author:

Saurabh Shrivastava

Assistant Professor,

Shri Rawatpura Sarkar Institute of

Pharmacy, Kumhari - 490042,

Chhattisgarh, India.

E-mail: saurabhshri1991@gmail.com

\begin{abstract}
Mebendazole is a broad-spectrum anthelmintic drug that is widely used in the treatment of helminthic infections. A simple, accurate, and precise UV-visible spectrophotometric method has been developed and validated for the determination of Mebendazole in tablet formulation. The solvent used for the development of the proposed method was Phosphate buffer 6.8 at $278.6 \mathrm{~nm}$. The Beers' law was obeyed in the concentration range $5-30 \mu \mathrm{g} / \mathrm{ml}$. The developed method was validated as per ICH guidelines such as linearity, accuracy, precision, the limit of detection, the limit of quantification, and robustness. The correlation coefficient was found to be 0.999 . The accuracy was found between 99.22 to $99.54 \%$. The \% RSD of Mebendazole was found to 0.05 to 0.20 for intraday and 0.05 to 0.15 for inter-day precision. The method was found to be precise as \% RSD was found to be less than $2 \%$. The LOD and LOQ were found to be $0.986 \mu \mathrm{g} / \mathrm{ml}$ and $2.988 \mu \mathrm{g} / \mathrm{ml}$, respectively. The results demonstrated that the excipients in the commercial tablets did not interfere with the method and can be conveniently employed for routine quality control analysis of Mebendazole in pharmaceutical tablets formulations.
\end{abstract}

INTRODUCTION: Mebendazole (MBZ) is a broad spectrum anthelmintic drug of the benzimidazole class. Chemically, MBZ is methyl-5 - benzoyl benzimidazole - 2 - carbamate. It is available in tablets, syrup, or suspension dosage forms ${ }^{1-2}$. Mebendazole is commonly used to treat pinworm, whipworm, roundworm, and hookworm infections. It has poor aqueous solubility and oral bioavailability ${ }^{3-4}$. It causes many adverse effects such as anemia and liver damage in high doses. It is a well-known anthelmintic drug, but due to its poor aqueous solubility, low bioavailability, and high first-pass metabolism, it has not achieved the therapeutic efficacy of the drug ${ }^{5-7}$.

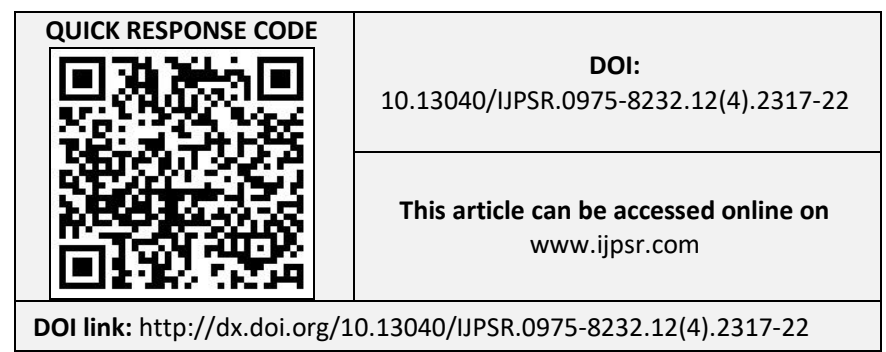

A literature survey had been revealed various analytical methods such as HPLC ${ }^{7-9}$, HPTLC ${ }^{8,9}$, and Spectroscopic ${ }^{10}$ methods for the determination of Mebendazole drug in the pharmaceutical formulation alone or combination with other drugs. In this study, efforts were made to develop a simple, easy and economical UV spectrophotometric method using suitable solvent for the determination of Mebendazole in the raw materials as well as in the marketed dosage formulations. The International Conference on Harmonization (ICH) guidelines under section Q2 (R1) was used to validate the developed method ${ }^{11-13}$.

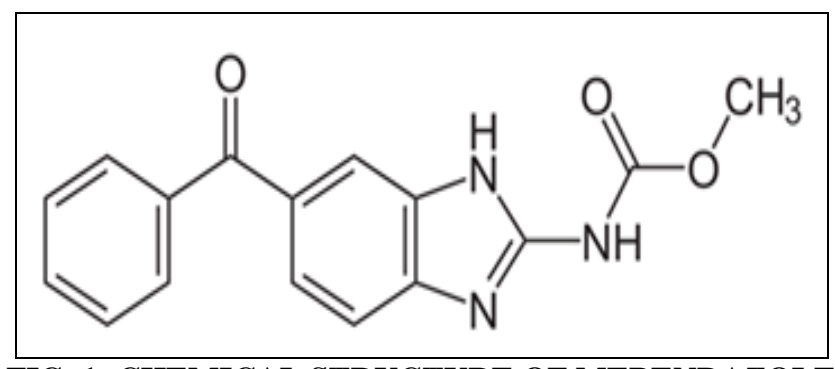

FIG. 1: CHEMICAL STRUCTURE OF MEBENDAZOLE 


\section{MATERIALS AND METHODS:}

Materials: Mebendazole was obtained from Medopharm, Chennai, Tamil Nadu, India, as a gift sample. All the other chemicals and reagents used were of analytical grade and purchased from Sigma Aldrich. The pharmaceutical tablets of Mebendazole (VERMOX 500) were procured from a local Pharmacy shop.

Instrumentation: Spectroscopic analysis was carried out using Double beam UV-Visible Spectrophotometer-1800, Shimadzu (Kyoto, Japan) with $10 \mathrm{~mm}$ path length matched quartz cells.

Selection of Solvent: The criterion for the selection of solvent is based on solubility. The solubility of Mebendazole was determined by using a variety of solvents.

Preparation of Standard Stock Solution and Working Solution: Accurately weighed $100 \mathrm{mg}$ of pure Mebendazole drug and transferred into a 100 $\mathrm{ml}$ volumetric flask. A small quantity of Phosphate buffer 6.8 was added to ensure complete solubilization of the drug, and finally, volume was made up to the mark with the same buffer solution. The solution was sonicated for $5 \mathrm{~min}$ to dissolve and remove air completely.

The standard stock solution was obtained having a concentration of $1000 \mu \mathrm{g} / \mathrm{ml}$. From this stock solution, $10 \mathrm{ml}$ was taken into a $100 \mathrm{ml}$ volumetric flask, diluted up to $100 \mathrm{ml}$ with Phosphate buffer 6.8 to get them working solution of $100 \mu \mathrm{g} / \mathrm{ml}$, and filtered through Whatman filter paper before analyzing.

Preparation of Calibration Curve: From the working solution, $0.5,1.0,1.5,2.0,2.5$, and $3.0 \mathrm{ml}$ solution was transferred into a series of calibrated $10 \mathrm{ml}$ volumetric flasks, and the volume was made up using Phosphate buffer 6.8. The solutions were scanned in the range of 200 to $400 \mathrm{~nm}$ against a blank (Phosphate buffer 6.8).

Method Validation: The proposed analytical method has been validated as per the guideline of the International Conference on Harmonization (ICH) under section Q2 (R1) for the following parameters such as linearity, accuracy, precision, the limit of detection (LOD), limit of quantification (LOQ) and robustness ${ }^{13-16}$.
Linearity: The linearity of the analytical method is the ability of that method to produce results that are directly proportional to the concentration of the analyte in samples with a given range ${ }^{17-19}$. The serial dilution was prepared in the range of 5-30 $\mu \mathrm{g} / \mathrm{ml}$ from the working solution. The samples were analyzed by a UV spectrophotometer using phosphate buffer 6.8 as a blank, and the obtained data were used for the linearity calibration curve.

Accuracy: An accuracy of the proposed method was determined to check the recovery of the test sample by using the standard addition method. The recovery of the method was estimated by spiking the sample solution at three different levels 80, 100, and $120 \%$. The accuracy was reported as \% recovery \pm (\% confidence interval) with $\%$ relative error on the base of actual and estimated concentrations ${ }^{20}$.

Precision: A precision of the proposed method was performed to check the degree of repeatability of the method. In this method, the sample was measured at least three times on the same day at intervals of an hour for an inter-day study and three different days for inter-day study ${ }^{21}$. The standard deviation (SD) and relative standard deviation (RSD) were calculated.

\section{Limit of Detection (LOD) and Limit of} Quantification (LOQ): The LOD and LOQ were performed to check the sensitivity of the method. For this study six replicates of the analyte at the lowest concentration were measured and quantified. LOD measures the limit of the method to detect the minimum concentration of an analyte in the sample; however undoubtedly quantitated as an exact value ${ }^{20-22}$. The LOQ may be defined as the limit of minimum detection capacity of the method to analyze the analyte in a sample which shows the quantitated reliably with the specified level of accuracy and precision ${ }^{23}$.

Robustness: The robustness of the proposed method is the ability to remain unaffected by deliberate variations in method parameters. It was determined by altering the $\lambda$ max of the analysis by $\pm 2 \mathrm{~nm}$. The $\%$ mean recovery $( \pm \%$ confidence interval), as well as \% relative error, were determined ${ }^{23,24}$. The analysis of the standard pure drug of Mebendazole solution in phosphate buffer 6.8 was performed at different wavelengths $( \pm 2 \mathrm{~nm})$. 
Ruggedness: The ruggedness of the analytical method is the degree of reproducibility of test results obtained by analysis of the same samples under a variety of normal test conditions on different days and by different analysts ${ }^{23-25}$.

Assay of Marketed Formulation: The newly proposed method was applied to analyze the marketed formulation of Mebendazole (VERMOX $500 \mathrm{mg}$ ). Ten tablets were weighed and finally powdered in a pestle mortar. The drug powder equivalent to $10 \mathrm{mg}$ was weighed accurately and moved to a $100 \mathrm{ml}$ volumetric flask, dissolved in about $40 \mathrm{ml}$ of Phosphate buffer 6.8, and sonicated for $10 \mathrm{~min}$ to get a clear solution of $100 \mu \mathrm{g} / \mathrm{ml}$. The volume was made up to the mark with the same buffer to obtain a sample solution.

The solution was then filtered through Whatman filter paper \#44 23- 25. This filtrate was diluted suitably with the same buffer to get the solution concentration of $10 \mu \mathrm{g} / \mathrm{ml}$. The absorbance of the sample solution was measured at $278.6 \mathrm{~nm}$ using Phosphate buffer 6.8 as the blank.
RESULTS AND DISCUSSION: The new analytical method was developed, optimized, validated, and applied for the quantitative analysis of pure drug and marketed tablets formulation.

Method Development: The reported methods or the estimation of Mebendazole are complex, timeconsuming, require a large number of solvents, and also require high costly equipment. In the present work, an inexpensive, nontoxic solvent was chosen to get a simple, cost-effective and eco-friendly UV spectrophotometric method for the determination of Mebendazole in a tablet formulation. Based on solubility analysis, Phosphate buffer 6.8 was selected as a solvent for the experiment. The Maximum absorption $\left(\lambda_{\max }\right)$ of Mebendazole in Phosphate buffer 6.8 was found to be $278.6 \mathrm{~nm}$.

Method Validation: The proposed method was validated as per ICH guidelines for its linearity, accuracy, precision, robustness, the limit of detection, the limit of quantitation, and robustness. The overall results of the validation parameters were compiled in Table 1.

TABLE 1: VALIDATION PARAMETERS FOR DETERMINATION OF MEBENDAZOLE IN PHOSPHATE BUFFER 6.8

\begin{tabular}{ccc}
\hline S. no. & Parameters & Values \\
\hline 1. & Absorption maxima $(\mathrm{nm})$ & $278.6 \mathrm{~nm}$ \\
2. & Linearity range $(\mu \mathrm{g} / \mathrm{ml})$ & $5-30$ \\
3. & Regression Equation & $\mathrm{y}=0.033 \mathrm{x}+0.004$ \\
4. & Correlation coefficient $\left(\mathrm{r}^{2}\right)$ & 0.999 \\
5. & Accuracy $(\%$ recovery $\pm \mathrm{SD})$ & $99.22 \pm 0.18$ to $99.54 \pm 0.10$ \\
6. & Precision $(\% \mathrm{RSD})$ & Intraday assay $=0.05$ to 0.20 \\
7. & Interday assay $=0.05$ to 0.15 \\
8. & LOD $(\mu \mathrm{g} / \mathrm{ml})$ & 0.986 \\
\hline
\end{tabular}

Linearity: The UV spectrum and the calibration curve of Mebendazole in phosphate buffer 6.8 at $278.6 \mathrm{~nm}$ are shown in Fig $\mathbf{2}$ and figure 3, respectively. The linearity of Mebendazole was found to be in the range of $5-30 \mu \mathrm{g} / \mathrm{ml}$ with a correlation coefficient of 0.999 .

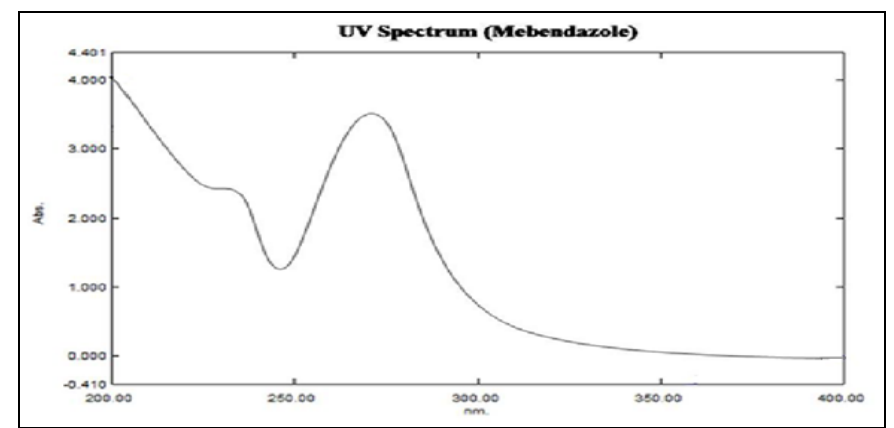

FIG. 2: UV SPECTRUM OF MEBENDAZOLE IN
PHOSPHATE BUFFER $6.8(5 \mu \mathrm{g} / \mathrm{ml})$

FIG. 2: UV SPECTRUM OF MEBENDAZOLE IN
PHOSPHATE BUFFER $6.8(5 \mu \mathrm{g} / \mathrm{ml})$
The linearity of Mebendazole was shown in Table 2. The significant linear regression is validated by the ANOVA test within the F value. It is observed from the result obtained that the $\mathrm{F}$ calculated value is greater than F critical at $278.6 \mathrm{~nm}$.

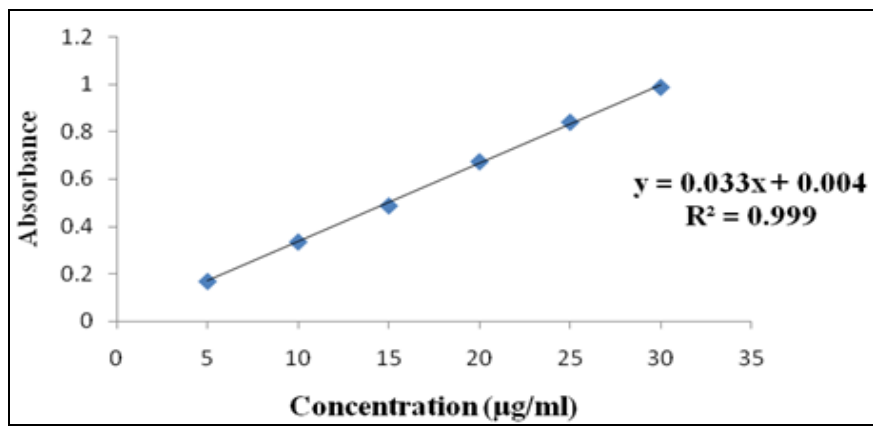

FIG. 3: CALIBRATION CURVE OF MEBENDAZOLE 
TABLE 2: LINEARITY OF MEBENDAZOLE

\begin{tabular}{cc} 
Concentration $(\boldsymbol{\mu g} / \mathbf{m l})$ & Absorbance Value \\
\hline 5 & 0.170 \\
10 & 0.336 \\
15 & 0.488 \\
20 & 0.674 \\
25 & 0.84 \\
30 & 0.987 \\
Average & 0.5825 \\
Regression equation & $\mathrm{y}=0.033 \mathrm{x}+0.004$ \\
$\mathrm{r}^{2}$ & 0.999 \\
\hline
\end{tabular}

Accuracy: The accuracy of the proposed method was estimated by a recovery study at the three-level of percentage addition.

As shown in Table 3, the percentage recovery of Mebendazole was found to be in the range of 99.22 to 99.54. The results of the recovery studies undoubtedly demonstrate the accuracy of the proposed method.

TABLE 3: ESTIMATION OF ACCURACY BY \% RECOVERY METHOD

\begin{tabular}{|c|c|c|c|}
\hline Concentration $(\mu \mathrm{g} / \mathrm{ml})$ & Level of Addition (\%) & $\begin{array}{l}\text { Amount of Drug Found }(\boldsymbol{\mu g}) \\
\text { Mean } \pm \mathrm{SD}^{*}\end{array}$ & $\%$ Mean Recovery \pm \% RSD \\
\hline \multirow[t]{3}{*}{10} & 80 & $07.92 \pm 0.03$ & $99.22 \pm 0.18$ \\
\hline & 100 & $09.95 \pm 0.01$ & \\
\hline & 120 & $11.89 \pm 0.01$ & \\
\hline \multirow[t]{3}{*}{15} & 80 & $11.86 \pm 0.02$ & $99.34 \pm 0.08$ \\
\hline & 100 & $14.97 \pm 0.01$ & \\
\hline & 120 & $17.88 \pm 0.01$ & \\
\hline \multirow[t]{3}{*}{20} & 80 & $15.88 \pm 0.04$ & $99.54 \pm 0.10$ \\
\hline & 100 & $19.95 \pm 0.03$ & \\
\hline & 120 & $23.91 \pm 0.02$ & \\
\hline
\end{tabular}

* $(\mathrm{n}=3)$ determinations

Precision: The precision of the proposed method was carried out by repeating the complete experiment with different analysts on different days under the same laboratory environment. The \% RSD of Mebendazole was found to 0.05 to 0.20 for intraday and 0.05 to 0.15 for inter-day precision. The results of intraday and inter-day precision were shown in Table 4. The developed method was found to be precise as the \% RSD values of intraday and inter-day studies were found less than $2 \%$.

TABLE 4: INTRADAY AND INTERDAY PRECISION

\begin{tabular}{ccccc}
\hline Concentration $(\boldsymbol{\mu g} / \mathbf{m l})$ & \multicolumn{2}{c}{ Intraday Precision } & \multicolumn{2}{c}{ Inter-day Precision } \\
\cline { 2 - 5 } & Mean $\mathbf{\pm}$ SD $*$ & \% RSD & Mean \pm SD* & \% RSD \\
\hline 10 & $09.96 \pm 0.02$ & 0.20 & $09.92 \pm 0.01$ & 0.15 \\
15 & $14.96 \pm 0.01$ & 0.06 & $14.92 \pm 0.01$ & 0.06 \\
20 & $19.97 \pm 0.01$ & 0.05 & $19.93 \pm 0.01$ & 0.05 \\
\hline
\end{tabular}

* $(\mathrm{n}=3)$ determinations

Limit of Detection (LOD) and Limit of Quantification (LOQ): The LOD and LOQ study was performed to check the sensitivity of the proposed developed method. The LOD and LOQ were found to be $0.986 \mu \mathrm{g} / \mathrm{ml}$ and $2.988 \mu \mathrm{g} / \mathrm{ml}$, respectively. From the obtained results, it can be easily interpreted that this UV method is highly sensitive to analyze Mebendazole.
Robustness: The robustness of the developed method shows a non-significant influence of the absorption level through the analysis of the Mebendazole solution in Phosphate buffer 6.8 at different wavelengths $( \pm 2 \mathrm{~nm})$. The result of the robustness study was shown in Table 5.

TABLE 5: ROBUSTNESS STUDY

\begin{tabular}{ccccccc}
\hline \multirow{2}{*}{ Concentration } & $(\boldsymbol{\mu} \mathbf{g} / \mathbf{m l})$ & \multicolumn{3}{c}{ At 276.6 nm } & \multicolumn{3}{c}{ At 280.6 nm } \\
\cline { 2 - 6 } & Absorbance & Mean \pm SD & \%RSD & Absorbance & Mean \pm SD & \% RSD \\
\hline \multirow{2}{*}{10} & 0.327 & $0.32 \pm 0.004$ & 1.423 & 0.324 & $0.32 \pm 0.003$ & 1.123 \\
& 0.321 & & & 0.322 & \\
& 0.318 & & & 0.317 & \\
\hline
\end{tabular}

Ruggedness: As shown in Table 6, it was observed that there were no significant changes in the result by changing an analyst, which confirmed that the developed method is rugged. 
TABLE 6: RUGGEDNESS STUDY

\begin{tabular}{cclcccccc}
\hline Conc. $(\boldsymbol{\mu g} / \mathbf{m l})$ & \multicolumn{4}{c}{ Analyst 1 } & \multicolumn{4}{c}{ Analyst 2 } \\
\cline { 2 - 9 } & Absorbance & $\begin{array}{l}\text { Mean } \pm \\
\text { SD }\end{array}$ & $\begin{array}{l}\text { \% } \\
\text { RSD }\end{array}$ & $\begin{array}{l}\text { Recovery } \\
\text { \% }\end{array}$ & Absorbance & Mean \pm & \% & \multicolumn{2}{l}{ Recovery } \\
SD & RSD & \% \\
\hline 10 & 0.336 & $0.334 \pm$ & 0.96 & 99.60 & 0.337 & $0.335 \pm$ & 0.78 & 99.70 \\
10 & 0.331 & 0.003 & & & 0.336 & 0.002 & & \\
10 & 0.337 & & & & 0.332 & & \\
\hline
\end{tabular}

Assay of Marketed Formulation: The developed and validated method was applied for the estimation of the drug in marketed tablet formulation.
The result of the assay of the marketed formulation was shown in Table 7. The \% assay was found to be 97.3. The developed method was a good agreement with the label claim.

TABLE 7: RESULTS FOR ASSAY OF MARKETED FORMULATION

\begin{tabular}{ccccc}
\hline Compound Name & Amount Label (mg) & Amount Found (mg)* & \%RSD & \% Assay \\
\hline Mebendazole & 500 & 486.54 & 0.11 & $97.30 \%$ \\
\hline$*(\mathrm{n}=3)$ determinations & & & &
\end{tabular}

CONCLUSION: The UV spectroscopic method for the determination of Mebendazole has been developed and validated as per the guidelines of the International Conference on Harmonization (ICH) under section Q2 (R1). The method found to be simple, reliable, more accurate and precise with lower limits of detection, more specific quantification and sensitivity. It is concluded that from the results obtained, the analysis of validation parameters proved that the method is reproducible and efficient for the determination of Mebendazole pure drug and in tablet formulations without any interferences from excipients. Hence, the method can be used for routine analysis of bulk drug and formulations and can also be used for bioequivalence studies.

ACKNOWLEDGMENT: The authors are grateful to Medopharm, Chennai, Tamil Nadu, India, for providing Mebendazole as a gift sample. The authors would like to thank Shri Rawatpura Sarkar Institute of Pharmacy, Kumhari for providing the necessary facilities to carry out this research work.

CONFLICTS OF INTEREST: The authors declare no conflicts of interest.

\section{REFERENCES:}

1. Dhandar AG, Ganorkar SB, Patil AS and Shirkhedkar AA: Development and validation of UV spectrophotometric method for simultaneous estimation of Quinfamide and Mebendazole in in-house pharmaceutical formulation. Journal of Pharmaceutical Technology Research and Management 2018; 6(1): 9-20.

2. Shrivastava S, Gupta A and Kaur CD: The epitome of novel techniques and targeting approaches in drug delivery for treating lymphatic filariasis. Current Drug Targets 2020; 21: 1250-63.
3. Attia KA, Nassar MW, El-Dosoky M and Madkour AW: Spectrophotometric methods for determination of mebendazole in presence of its alkaline induced degradation product in pure form and pharmaceutical preparation. Ijppr Human 2015; 4(3): 1-9.

4. Mrus J, Baeten B, Engelen M and Silber SA: Efficacy of single-dose $500 \mathrm{mg}$ mebendazole in soil-transmitted helminth infections: a review. Journal of Helminthology 2018; 92(3): 269-78.

5. Shrivastava S, Gidwani B and Kaur CD: Development of mebendazole loaded nanostructured lipid carriers for lymphatic targeting: Optimization, characterization, invitro and in-vivo evaluation. Particulate Science and Technology 2020; 11: 1-1.

6. Guerini AE, Triggiani L, Maddalo M, Bonù ML, Frassine F, Baiguini A, Alghisi A, Tomasini D, Borghetti P, Pasinetti N and Bresciani R: Mebendazole as a candidate for drug repurposing in oncology: An extensive review of current literature. Cancers 2019; 11(9): 1284.

7. Shrivastava S, Gidwani B, Gupta A and Kaur CD: Ethnopharmacological approaches to treat lymphatic filariasis. International Journal of Pharmacy and Analytical Research 2016; 5(3): 445-70.

8. Parakh DR, Madagul JK, Mene HR, Patil MP and Kshirsagar SJ: RP-HPLC method development and validation for Quantification of Mebendazole in API and Pharmaceutical Formulations. Pharma Tutor 2016; 4(5): 46-51.

9. Naguib IA, Hassan ES, Emam AA and Abdelaleem EA: Development and Validation of HPTLC and Green HPLC Methods for Determination of a New Combination of Quinfamide and Mebendazole. Journal of Chromatographic Science 2020; 58: 16-21.

10. Shah U, Talaviya $\mathrm{T}$ and Gajjar A: Development and validation of derivative spectroscopic Method for the simultaneous estimation of mebendazole and levamisole hydrochloride in pharmaceutical formulations. International Journal of Pharmaceutical Chemistry and Analysis 2015; 2(2): 108-12.

11. Guideline IH: Validation of analytical procedures: text and methodology Q2 (R1). In International conference on harmonization Geneva Switzerland 2005; 10; 11.

12. Borman P and Elder D: Q2 (R1) validation of analytical procedures. ICH Quality Guidelines 2017; 127-66. 
13. Shrivastava S, Deshpande $P$ and Daharwal SJ: Key Aspects of Analytical Method Development and Validation. J of Ravishankar University 2018; 31(1): 32-9.

14. Piponski M, Stoimenova TB, Stefov S, Balkanov T, Serafimovska GT and Logoyda L: Development of a novel, fast, simple, nonderivative HPLC method with direct UV measurment for quantification of memantine hydrochloride in tablets. Journal of Separation Science 2020; 43: 3482-90.

15. Rao AL, Prasanthi T, Raju BP, Sravanthi I, Sri KH, Prasanthi K and Sravan V: UV spectrophotometric method development and validation for simultaneous estimation of alprazolam and mebeverine hydrochloride in bulk drug and pharmaceutical formulation. International $\mathbf{J}$ of Res in Ayush and Pharmaceutical Sciences 2017; 27-32.

16. Subramaniam AT, Velmurugan D, Ramanathan S, Dhanabalan K, Munusamy $J$ and Gampala $\mathrm{H}$ : Development and validation of RP-HPLC/UV methods for the estimation of Risedronate sodium in pure and pharmaceutical dosage form. Journal of Pharmaceutical Chemistry 2019; 17: 5-8.

17. Daharwal SJ and Shrivastava S: HPTLC Method Development and Validation for Quantification of Quercetin in Thuja occidentalis Mother tincture. Research Journal of Pharmacy and Technology 2019; 12(9): 4102-6.

18. Shrivastava S, Shrivastava S and Daharwal S: A Validated UV Spectrophotometry Method for the Quantification of Reserpine in Rauwolfia serpentina Mother Tincture. Journal of Pharmaceutical Research 2020; 1(01): 35-40.

19. Sowjanya G, Pallavi DP, Mazumder O and Kumar SP: Development and Validation of a New Derivative UV
Spectrophotometric Method for Simultaneous Quantification of Tizanidine and Aceclofenac in Tablets. Research Journal of Pharmacy and Technology 2020; 13(2): 569-74.

20. Chanda I, Bordoloi R, Chakraborty DD, Chakraborty P and Das SR: Development and Validation of UVSpectroscopic Method for Estimation of Niacin in Bulk and Pharmaceutical Dosage Form. Journal of Applied Pharmaceutical Science 2017; 7(09): 081-4.

21. Khodke VS: Development and validation of novel ultraviolet spectrophotometric method for quantitative estimation of dalfampridine in bulk and in pharmaceutical formulation development 2019; 12: 275-79.

22. Narang JK: Development and Validation of Ultraviolet Spectrophotometric Method for Estimation of Frovatriptan Succinate Monohydrate in Bulk and Pharmaceutical Dosage form. Asian Journal of Pharmaceutics (AJP): Free full text articles from Asian J Pharm 2018; 12: 195-201.

23. Shrivastava $S$, Shrivastava $S$ and Tiwle R: Validation of novel UV Spectrophotometric method for the determination of Ketoconazole in Pharmaceutical Formulation. J Pharm Adv Res 2020; 3(2): 793-98.

24. Bhadauria RS and Agarwal V: Development and Validation of UV Spectroscopic Method for Simultaneous Estimation of Dapagliflozin and Saxagliptin in marketed formulation. Journal of Drug Delivery and Therapeutics 2019; 9(4): 1160-4.

25. Shah AB, Dedania Z and Jain VC: Development and validation of UV spectroscopic simultaneous method for Zonisamide and Cilostazol in synthetic mixture. Pharma Science Monitor 2019; 10: 53-65.

\section{How to cite this article:}

Shrivastava S and Kaur CD: Development and validation of novel UV spectrophotometric method for the determination of mebendazole in pharmaceutical formulation. Int J Pharm Sci \& Res 2021; 12(4): 2317-22. doi: 10.13040/IJPSR.0975-8232.12(4).2317-22.

All @ 2013 are reserved by the International Journal of Pharmaceutical Sciences and Research. This Journal licensed under a Creative Commons Attribution-NonCommercial-ShareAlike 3.0 Unported License.

This article can be downloaded to Android OS based mobile. Scan QR Code using Code/Bar Scanner from your mobile. (Scanners are available on Google Playstore) 